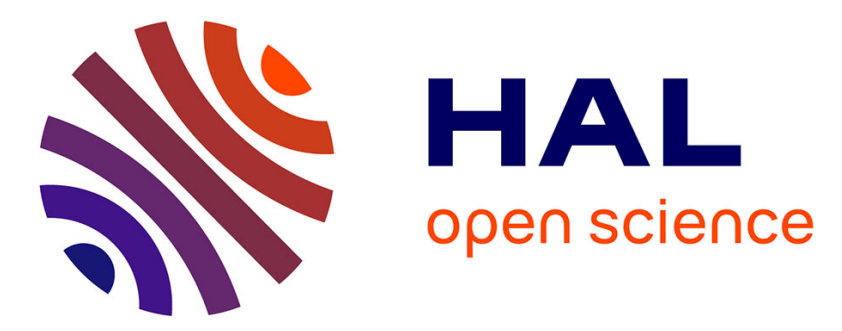

\title{
Profiling of Organic Compounds in Bioethanol Samples of Different Nature and the Related Fractions
}

Carlos Sánchez, Sergio Santos, Raquel Sánchez, Charles-Philippe Lienemann, José-Luis Todolí

\section{- To cite this version:}

Carlos Sánchez, Sergio Santos, Raquel Sánchez, Charles-Philippe Lienemann, José-Luis Todolí. Profiling of Organic Compounds in Bioethanol Samples of Different Nature and the Related Fractions. ACS Omega, 2020, 5 (33), pp.20912-20921. 10.1021/acsomega.0c02360 . hal-03114206

\section{HAL Id: hal-03114206 \\ https: / hal-ifp.archives-ouvertes.fr/hal-03114206}

Submitted on 18 Jan 2021

HAL is a multi-disciplinary open access archive for the deposit and dissemination of scientific research documents, whether they are published or not. The documents may come from teaching and research institutions in France or abroad, or from public or private research centers.
L'archive ouverte pluridisciplinaire HAL, est destinée au dépôt et à la diffusion de documents scientifiques de niveau recherche, publiés ou non, émanant des établissements d'enseignement et de recherche français ou étrangers, des laboratoires publics ou privés.

\section{(ㄷ)(1) $\$$}

Distributed under a Creative Commons Attribution - NonCommerciall 4.0 International 


\title{
Profiling of Organic Compounds in Bioethanol Samples of Different Nature and the Related Fractions
}

\author{
Carlos Sánchez, Sergio Santos, Raquel Sánchez, Charles-Philippe Lienemann, and José-Luis Todolí* \\ Cite This: ACS Omega 2020, 5, 20912-20921 \\ Read Online
}

ABSTRACT: Forty-one bioethanol real samples and related fractions, together with a biobutanol sample, have been analyzed with gas chromatography coupled to either mass spectrometry (GC-MS) or flame ionization detection (GC-FID). Bioethanol with different water contents, samples originated from several sources of biomass, first- as well as secondgeneration specimens, distillation fractions, samples stocked in containers made of four different materials, and, finally, a biobutanol sample have been

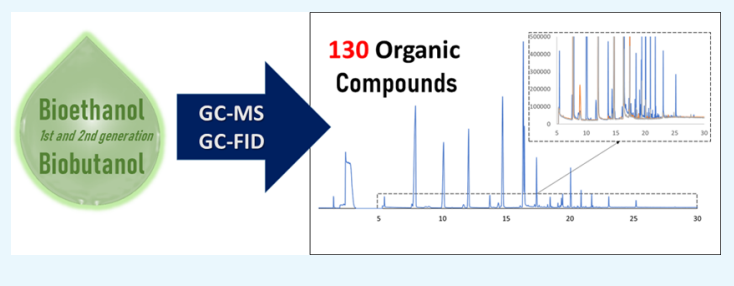
analyzed. The number of the compounds found through GC-MS has been 130, including alcohols, aldehydes, ketones, esters, ethers, nitrogen compounds, organic acids, furane derivates as well as other species (e.g., limonene). Afterward, a quantitative determination of major components of bioethanol has been carried out. The achieved results have revealed that, besides ethanol and, in some cases, water, species such as acetaldehyde, methanol, and higher alcohols, as well as 1,1-diethoxyethane, may be present at concentrations above $500 \mathrm{mg} \mathrm{L}^{-1}$. While the source of bioethanol (nature of the raw material, ethanol generation, or water content) has a direct impact on its volatile organic compound (VOC) profile, the material of the container where the biofuel has been stored does not play a significant role. Finally, the results have demonstrated that, for a given production process, different distillation fractions contain unequal VOC profiles.

\section{INTRODUCTION}

Bioethanol has been considered as an effective alternative source of energy. The use of this biofuel may reduce the emission of greenhouse gases by $75 \%$ with respect to fossil fuels. $^{1-6}$ As a result, its production and consumption have grown exponentially during the past two decades. $4,7,8$ Bioethanol can be directly used, in its pure form, within modified spark-ignition engines or it can be blended with gasoline or diesel fuels. ${ }^{8}$ Even though one liter of ethanol contains $66 \%$ of the energy provided by a liter of petrol, it is used in the blend as a very efficient octane-boosting agent, thereby substituting chemical additives such as methyl tert butyl ether (MTBE) or tetraethyl lead. ${ }^{1,3,4,9,10}$

There are two main sources of bioethanol: The so-called first-generation bioethanol is an alcoholic product generated from simple sugars (e.g., sugarcane or sugar beet), seeds, or starch (e.g., potato, corn, and wheat) using diverse types of microorganisms. Generally, yeasts convert sugars into ethanol by fermentation. Afterward, the resulting syrup is distilled and dehydrated. ${ }^{9}$ The conversion of starch and sugars to ethanol is relatively simple and efficient in terms of energy consumption. Nevertheless, only a limited fraction of the raw material is actually used to obtain bioethanol. This causes the main drawback of first-generation bioethanol, namely, the fuel-food competition. ${ }^{1,9}$ To solve this problem, the second-generation bioethanol has appeared. The raw materials used to obtain it are agricultural nonedible lignocellulosic biomass issued from food crop production or whole plant biomass. Therefore, an advantage of the second-generation bioethanol is the low cost of the resources because wastes generated by the food processing industry are used to obtain it. ${ }^{2,9,11}$ However, the use of these raw materials involves applying a previous enzymatic hydrolysis; thus, the equipment needed to obtain this type of bioethanol becomes more sophisticated and affords lower bioethanol yields than in the case of first-generation processes. $^{9}$ The third generation of biofuels, being implemented quickly in the case of biodiesel, ${ }^{12}$ is not established yet for bioethanol production.

At the end of the production process, bioethanol may contain inorganic pollutants ${ }^{13-16}$ as well as organic ${ }^{13,17,18}$ compounds whose presence may negatively affect its quality in different ways: (i) they may degrade the combustion efficiency; (ii) the catalyst and/or engines performance may also be worsened; (iii) these products may induce reactions among them or with ethanol, thus degrading its quality; and (iv) the gaseous emissions produced may be an important source of harmful volatile organic compounds (VOCs).

There exists limited legislation regarding the quality control of bioethanol. The specifications are focused on fuel blends of bioethanol and gasoline, ${ }^{19-21}$ denatured $^{22}$ or undenatured ${ }^{23}$

Received: May 20, 2020

Accepted: July 23, 2020

Published: August 10, 2020 
Table 1. Maximum Concentration Levels (\%, w/w) Allowed in the Existing Standards for Bioethanol Quality Control

\begin{tabular}{|c|c|c|c|c|c|}
\hline & $\begin{array}{l}\text { ASTM } \\
\text { D5798 }^{19}\end{array}$ & ASTM E3050 22 & $\begin{array}{l}\text { ASTM }^{23} \\
\text { E3237 }^{23}\end{array}$ & $\mathrm{EN} 15376^{20}$ & EN $15293^{21}$ \\
\hline $\mathrm{H}_{2} \mathrm{O}(\%)$ & $<1$ & $<10$ & & $<0.3$ & $<0.4$ \\
\hline $\mathrm{MeOH}(\%)$ & $<0.5$ & & & $<1$ & $<1$ \\
\hline $\begin{array}{l}\text { higher alcohols (C3- } \\
\text { C5) (\%) }\end{array}$ & & $<2$ & & $<2$ & $<6$ \\
\hline specific requirements & & $\begin{array}{l}\text { EtOH }>90 \% \text {; hydrocarbon } \\
\quad \text { contamination }<1 \%\end{array}$ & & $\begin{array}{l}\text { EtOH and saturated higher } \\
\text { alcohols }>98.7 \%\end{array}$ & $\begin{array}{l}\text { Acidity also tested with the corrosion } \\
\text { of the } \mathrm{Cu} \text { strip }\end{array}$ \\
\hline Acidity \% & $<0,005$ & $<0,004$ & $<0,007$ & $<0,007$ & $<0,005$ \\
\hline
\end{tabular}

ethanol. These regulations describe methodologies and maximum allowed levels of some compounds in this kind of fuels. The properties considered in the existing standards include vapor pressure of the blend, water content, percentage of methanol and higher alcohols, acidity, and denaturing agents or additives (e.g., dyes). Table 1 shows the maximum levels recommended by several standards.

As an alternative fuel, biobutanol is attracting increasing attention because of its advantages over bioethanol such as higher energy density, lower cost, the possibility of using it without any engine modification, and good compatibility with gasoline, among others. ${ }^{24}$ Furthermore, biobutanol can be used in the chemical industry as a precursor of compounds such as plasticizers, acrylate, and methacrylate esters, for instance. This alcohol can be biologically obtained from, for example, sugarcane, corn, rice, soy, as well as agricultural residues.

Although some methods have been developed for carrying out the determination of metals and metalloids in this kind of fuels, ${ }^{5,14}$ to the best of our knowledge, a limited number of articles related to the determination on organic compounds in bioethanol have been published. ${ }^{13,18}$ These studies are focused on major organic pollutants, and a small list of compounds has been quantified so far. Thus, Styarini et al. ${ }^{18}$ quantified eight organic compounds in only one sample of lignocellulosic bioethanol by means of gas chromatography-flame ionization detection, GC-FID. In a different study, Habe et al. ${ }^{13}$ applied GC-FID and gas chromatography-mass spectrometry, GCMS, for the analysis of a total of 13 first-generation bioethanol samples (mainly originating from sugarcane) only detecting 16 pollutants. Besides, these authors analyzed four secondgeneration ethanol specimens with 29 detected compounds other than ethanol. The objective of this work is thus to develop a method based on GC for a wide identification and quantification of volatile organic compounds in bioethanol and biobutanol samples. A GC-FID instrument was used for the determination of major compounds, whereas a GC-MS instrument was selected for identifying minor and trace organic components. The analysis of 41 bioethanol and 1 biobutanol real samples was performed with particular focus on (i) the effect of the raw materials used on the bioethanol organic profile, (ii) the impact of the number of distillation steps applied on the purity of the obtained biofuel, (iii) the bioethanol degradation during its storage in different materials, (iv) the comparison of first versus second-generation bioethanol, and (v) the evaluation of organic profiles for bioethanol and biobutanol.

\section{RESULTS AND DISCUSSION}

2.1. Identification of Volatile Compounds by Means of GC-MS. To identify the organic compounds present in the evaluated samples, experiments were first done by means of GC-MS coupling. Forty-two bioethanol real samples were analyzed by means of this coupling, and 130 different volatile compounds were identified. The analytes found, with an assigned probability above $94 \%$, were divided in ten categories according to their main functional group. The results for each group are described below, and the compounds found in each sample are summarized from Tables S2-S11. The cells highlighted in blue in these tables indicate the organic products found in, at least, one sample at high relative peak areas.

2.1.1. Alcohols. It should be noted that methanol could not be identified by means of this method because it eluted together with dissolved air and water present in the samples. However, this analyte was easily identified and quantified by GC-FID. A total of 23 additional alcohols such as 1-propanol, 2-butanol, i-butanol, 1-butanol, isoamyl alcohol, and amyl alcohol were present in the samples at relatively high levels (Table S2). Amyl alcohols have been detected in fusel oil (i.e., a byproduct generated during bioethanol production), and the occurrence of leucine and isoleucine in the raw material has been suggested to be the reason for their presence. ${ }^{25}$ All of these alcohols were expectedly originated as byproducts of the alcoholic fermentation. Some samples contained heavier alcohols as undecanol or tetradecanol, but their low relative areas suggested that they were present at trace levels. The appearance of heavy alcohols in biomass fermentation products is promoted by some metabolites such as amines. ${ }^{26}$

This analysis also determined that the main component present in sample B39 (biobutanol) was $i$-butanol instead of $n$ butanol, giving 1-butanol and 2-butanol as fermentation byproducts.

2.1.2. Aldehydes and Ketones. Fifteen analytes containing one of these functional groups were found in the samples (Table S3). The major analyte in this group was acetaldehyde, which appeared in several samples with a high relative peak area. Most of the analytes of this group could appear as a consequence of the incomplete fermentation process. Nevertheless, compounds such as acetaldehyde or formaldehyde could be added to water during the sugar extraction process to avoid the growth of bacteria, thus remaining in the final biofuel after the distillation process. ${ }^{27}$

2.1.3. Esters. Twenty-four mainly fatty acid ethyl esters (FAEE) were found in the samples (Table S4). They were likely the product of the reaction of organic acids or triacylglycerides, present in the samples as byproducts of the production process, with ethanol at a slightly acid $\mathrm{pH}$. For the analyzed samples, $\mathrm{pH}$ values ranged from 4.6 to 5 , which confirmed this possibility. The most abundant analytes in this group were ethyl acetate, ethyl propionate, ethyl butyrate, isoamyl acetate, ethyl valerate, and ethyl caproate. Other esters with a higher number of carbon atoms were found, but the areas of the peaks they generated were much lower than those for the previously mentioned compounds, suggesting that they 
were present at trace levels. It is worth noting that, for sample B39 (biobutanol), a specific ester profile was found. In this product, some of the FAEEs found in bioethanol were not present but peaks assigned to fatty acid isobutyl esters were detected. This fact suggested that fatty acids reacted with isobutanol.

2.1.4. Ethers. Seventeen ethers have been identified in the samples (Table S5), 1,1-diethoxyethane being present in virtually all of the biofuels. This compound has been reported to be the product of the reaction between ethanol and acetaldehyde. $^{28}$ The extent of this reaction depends on the $\mathrm{pH}$ of the sample, and, for this reason, acetaldehyde was not found in some samples.

2.1.5. Hydrocarbons. Table S6 shows the list of 17 hydrocarbons found in the biofuel samples. According to their relative peak area, they did not represent a significant fraction of the total content of VOCs other than ethanol. The major analyte, within this group, was $n$-hexane. It is worth noting that bicyclo[2.2.1] hepta-2,5-diene also appeared in the fractions of the distillation process (fractions $1-8$ ). The origin of these compounds is not clearly established in the literature, but they could be extracted from the raw material and would remain in the sample after distillation. Another hypothesis is that some of them could be a byproduct of the fermentation process or even formed during fuel storage. $^{29}$

2.1.6. Aromatic Hydrocarbons. Twelve aromatic hydrocarbons were detected in the bioethanol samples (Table S7). Toluene and the three isomers of xylene (m-xylene and pxylene appeared at the same retention time, whereas o-xylene eluted at longer times) prevailed over the remaining analytes of this group. Aromatic hydrocarbons could be probably extracted from the raw material in the first steps of the bioethanol production process.

2.1.7. Nitrogen Compounds. Ten nitrogen compounds were identified in the samples (Table S8), but the relative areas of the peaks they generated were very low. The possible origin of the nitrogen compounds was the raw material.

2.1.8. Organic Acids. Only two organic acids remained in the samples (Table S9), probably because they were converted into fatty acid ethyl esters, FAEEs, at the $\mathrm{pH}$ of the samples (around 5). These two acids were acetic acid in a great number of samples and isobutyric acid in the case of sample B39 (biobutanol) where isobutanol was the main component of the matrix. Organic acids could appear as a result of the ethanol or isobutanol oxidation during the fermentation step.

2.1.9. Furane Derivates. Sample B19 (lignocellulosic bioethanol) contained eight different furane derivates (Table S10). It should be noted that this sample is a secondgeneration bioethanol and the presence of furane and related compounds has been reported to be a consequence of noncomplete fermentation of lignocellulosic ethanol. ${ }^{30}$

2.1.10. Other Compounds. Six additional compounds were found in the samples that fell out of the previous groups (Table S11). Limonene appeared in a remarkable number of samples (i.e., 14). This compound could be easily extracted from the raw materials used in bioethanol production. Hexamethylcyclotrisiloxane is also present in numerous samples, and it is found to be the major $\mathrm{Si}$ compound formed from the degradation of poly(dimethylsiloxane), PDMS, which is used in many processes as a lubricant, for instance. ${ }^{31}$

2.1.11. Occurrence of Compounds. Figure 1 shows the number of samples in which each analyte was identified. The number of organic compounds (besides ethanol) that was

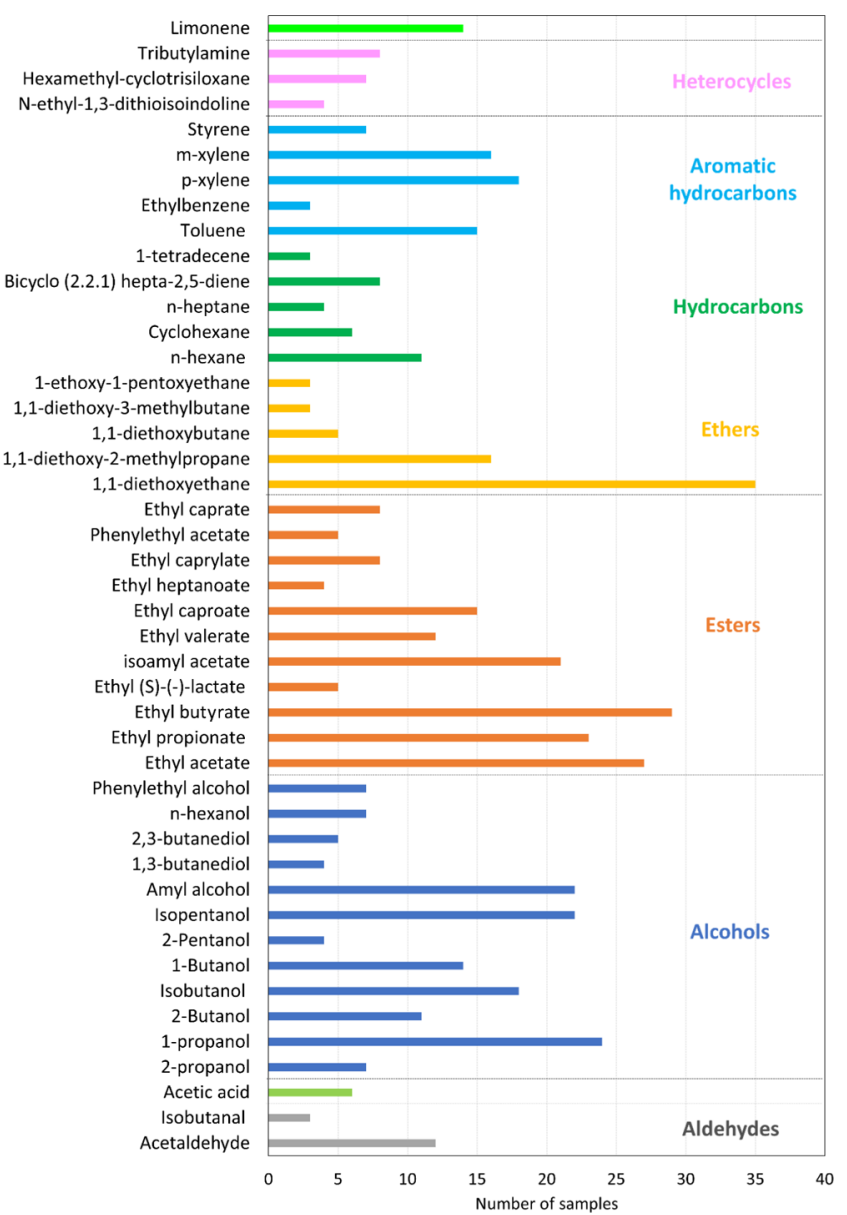

Figure 1. Frequency of identification of each analyte when $n \geq 3$.

found in the samples was very high (130 organic compounds in 42 samples). However, none of them were present in all of the samples. These two facts revealed that bioethanol production is a complex process and modifications in the process as well as in the raw material used may cause an alteration of the organic profile of the final bioethanol. In addition, the storage and transport conditions (i.e., temperature, $\mathrm{pH}$, humidity, hydration grade of bioethanol, etc.) could affect the volatile organic compound profile of the bioethanol samples since some of these species were products resulting from postproduction chemical reactions.

It should also be noted that alcohols and esters, synthesized by reactions between organic acids and alcohols, appeared as the predominant groups of compounds in bioethanol samples in terms of both the total number of compounds and concentration. Surprisingly, the most frequent chemical was an ether (1,1-diethoxyethane) that was present in 35 products ( $85 \%$ of the samples).

Other groups of compounds, such as hydrocarbons, aromatic hydrocarbons, and heterocycles, have been found in minor or at trace levels in a considerable number of samples. However, it should be taken into account that these compounds can severely affect the environment quality and the human health ${ }^{32,33}$ even at very low concentrations. Some aromatic hydrocarbons identified in the samples, such as benzene, toluene, ethylbenzene, and xylene (BTEX), have been widely recognized as human carcinogens and others also possess high toxicity, especially to the central nervous system of humans. ${ }^{32}$ Moreover, acetaldehyde was present in a 


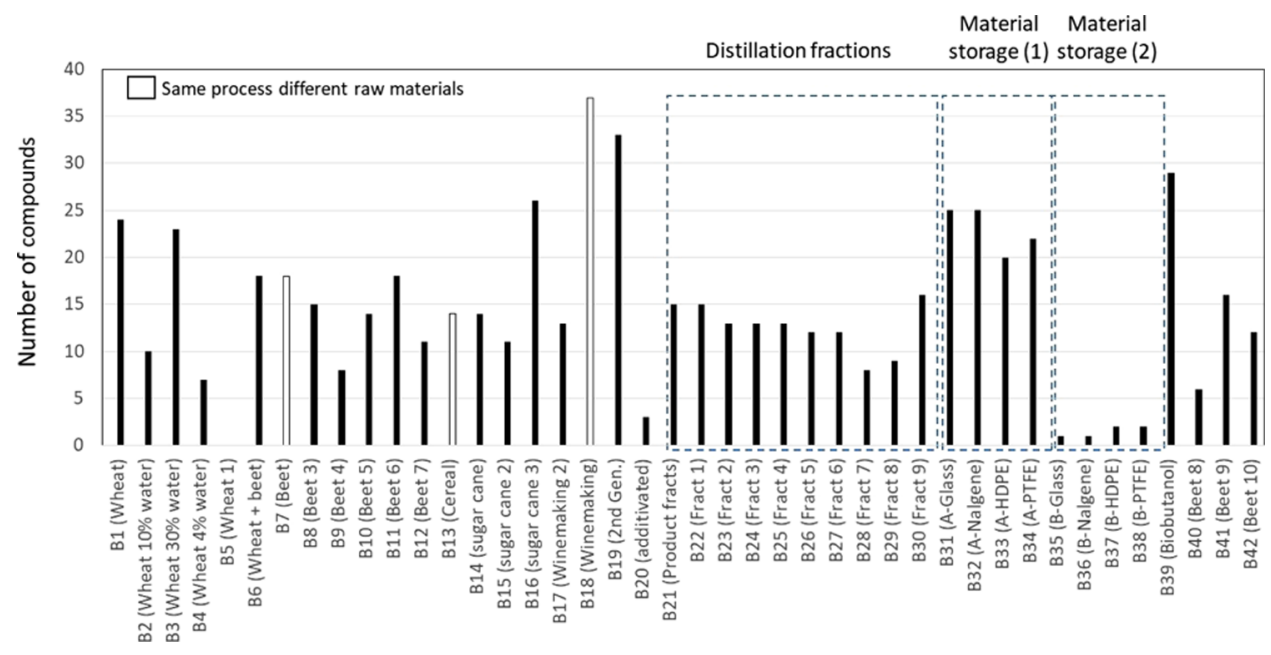

Figure 2. Number of compounds found in the samples by GC-MS.

significant number of bioethanol samples. This fact could explain the data reported by Niven ${ }^{10}$ related to an increase of acetaldehyde emission when $10 \%$ ethanol was added to gasoline (E10). Nevertheless, in the same study, it was reported that the addition of ethanol to gasoline lowered, compared with pure gasoline, the emission of other VOCs, such as xylene or toluene. ${ }^{10}$

Regarding the number of products found in the analyzed biofuels, sample B18 (i.e., bioethanol originated from winemaking wastes) yielded the highest number of peaks. A total of 37 compounds (together with methanol that could not be found by GC-MS) were identified in this sample (Figure 2). Additional samples, such as biobutanol (B39) or the secondgeneration bioethanol (B19), also contained a high number of organic compounds in their matrixes. Each one of these samples showed more than 30 peaks in GC-MS. Finally, around 25 organic species were detected in samples such as B1, $\mathrm{B} 3, \mathrm{~B} 16$, and the set from $\mathrm{B} 31-\mathrm{B} 34$, whereas the rest of the samples contained less than 25 organic compounds (Figure 2).

In the present study, some samples were selected to evaluate the effect of different variables on the number of organic compounds in the samples and their concentrations. Distillation fractions (fractions 1-9, Figure 2) were considered. As it was later established in GC-FID for major compounds, some VOCs were more concentrated in the lightest fraction and their concentration decreased in heavier ones. These species were acetaldehyde, ethyl acetate, bicyclo[2.2.1] hepta-2,5-diene, 1,1-diethoxyethane, and toluene. There was a direct relationship between the boiling point and the fractions where these analytes were present. Acetaldehyde, whose boiling point is $20.2^{\circ} \mathrm{C}$, was only present in the initial fractions ( 1 and 2). Ethyl acetate, with a boiling point of $77{ }^{\circ} \mathrm{C}$, appeared in fractions from 1 to 3 . However, bicyclo[2.2.1] hepta-2,5-diene (bp, $\left.89{ }^{\circ} \mathrm{C}\right), 1,1$-diethoxyethane (bp, $102{ }^{\circ} \mathrm{C}$ ), and toluene (bp, $111{ }^{\circ} \mathrm{C}$ ) were present at different abundancies in all of the fractions, except the final one (fraction 9) that corresponded to an aqueous fraction containing a dispersed organic phase.

Samples coming from several raw materials were also studied in detail. They were B18 from wine byproducts, B13 that is obtained using cereals as raw materials, and B7 that is generated using sugars extracted from beetroot. Sample B18 contained 37 different organic compounds, whereas the samples coming from cereals and beetroot were cleaner with only 14 and 18 volatile organic compounds, respectively (Figure 2).

The comparison between first-generation and secondgeneration bioethanol was also very interesting. As Figure 2 reveals, the second-generation sample (B19) contained a large number of organics (33 compounds), typically higher than the average number of organics generally present in the firstgeneration samples. This topic could be a source of further discussion and additional second-generation products should be analyzed.

2.2. Quantification of Major Volatile Compounds by Means of GC-FID. Once identified, major organic compounds were quantified according to GC-FID. The method was first validated and then applied to the analysis of the fuels tested.

2.2.1. Precision and Accuracy of the Chromatographic Method. The inter- and intraday precision of the method, in terms of the retention time and peak area, was evaluated. The precision obtained for the analytes when five chromatograms were obtained on the same day (intraday) and five different days (interday) was evaluated. In all of the cases, the area relative standard deviation, RSD, was lower than 7 and 9\% for intra- and interday runs, respectively. In terms of retention time, the variability was much lower than that observed in terms of peak area, the RSD being lower than 0.14 and $0.3 \%$ for intraday and interday studies, respectively.

Additionally, recoveries were obtained by means of the analysis of three real samples spiked with the analytes of interest at a $200 \mathrm{mg} \mathrm{L}^{-1}$ level. The recoveries for acetone, 2propanol, 1-propanol, 2-butanol, 1-butanol, 1,1-diethoxyethane, and isoamyl alcohol were not statistically different from $100 \%$. However, those for acetaldehyde were slightly lower than the target value. This may be caused by the loss of acetaldehyde in the auto-tautomeric equilibrium. In fact, the chromatograms obtained showed a peak at high retention times that corresponded to ethanol originated from the autotautomerization of this compound. ${ }^{34}$

2.2.2. Analysis of Real Samples. Table 2 summarizes the analytes identified in each sample and the concentration range at which they were found. For the sake of clarity, the concentrations have been classified into four groups $(<\mathrm{LOQ}$ $\mathrm{mg} \mathrm{L}^{-1}, \mathrm{LOQ}-100 \mathrm{mg} \mathrm{L}^{-1}, 100-500 \mathrm{mg} \mathrm{L}^{-1}$, and $>500 \mathrm{mg}$ $\mathrm{L}^{-1}$ ). The data not provided were below the LOQ (see Table S1). In general terms, it can be observed that acetaldehyde, 
Table 2. Quantitative Results for the Most Abundant Compounds Found in Bioethanol Real Samples ${ }^{a}$

\begin{tabular}{|c|c|c|c|c|c|c|c|c|c|c|c|c|c|c|c|c|c|c|c|c|c|c|c|c|c|c|c|c|c|c|c|c|}
\hline Analyte & 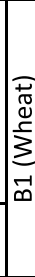 & 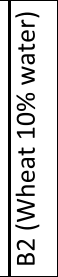 & 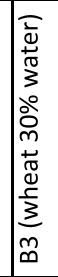 & 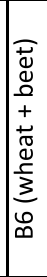 & 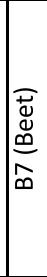 & 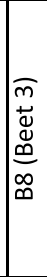 & 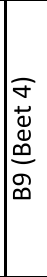 & 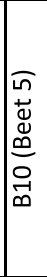 & 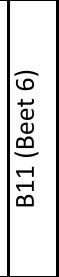 & 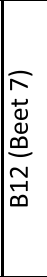 & 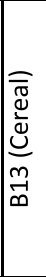 & 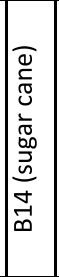 & 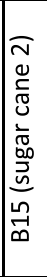 & 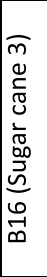 & 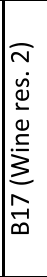 & 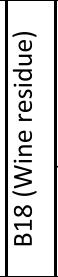 & 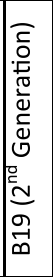 & 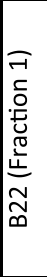 & 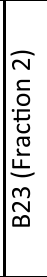 & 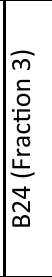 & 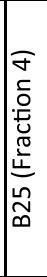 & 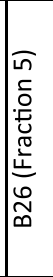 & 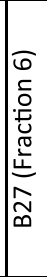 & 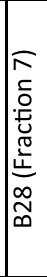 & 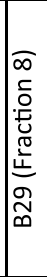 & 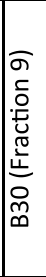 & 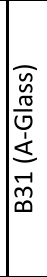 & 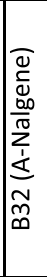 & 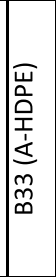 & 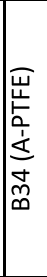 & 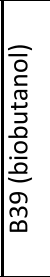 & 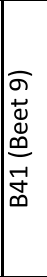 \\
\hline Acetaldehyde & & & & & & & & & & & & & & & & & & & & & & & & & & & & & & & & \\
\hline methanol & & & & & & & & & & & & & & & & & & & & & & & & & & & & & & & & \\
\hline Acetone & & & & & & & & & & & & & & & & & & & & & & & & & & & & & & & & \\
\hline 2-propanol & & & & & & & & & & & & & & & & & & & & & & & & & & & & & & & & \\
\hline 1-propanol & & & & & & & & & & & & & & & & & & & & & & & & & & & & & & & & \\
\hline 2-butanol & & & & & & & & & & & & & & & & & & & & & & & & & & & & & & & & \\
\hline i-butanol & & & & & & & & & & & & & & & & & & & & & & & & & & & & & & & & \\
\hline 1-butanol & & & & & & & & & & & & & & & & & & & & & & & & & & & & & & & & \\
\hline $\begin{array}{c}1,1- \\
\text { diethoxyethane }\end{array}$ & & & & & & & & & & & & & & & & & & & & & & & & & & & & & & & & \\
\hline $\begin{array}{l}\text { Isoamyl } \\
\text { alcohol }\end{array}$ & & & & & & & & & & & & & & & & & & & & & & & & & & & & & & & & \\
\hline
\end{tabular}

${ }^{a}$ Color code: red, $\mathrm{C}>500 \mathrm{mg} \mathrm{L}^{-1}$; orange, $100 \mathrm{mg} \mathrm{L}^{-1}<\mathrm{C}<500 \mathrm{mg} \mathrm{L}^{-1}$; green, LOQ $<\mathrm{C}<100 \mathrm{mg} \mathrm{L}^{-1}$; white, C $<$ LOQ. See Table S1 for LOQ values.

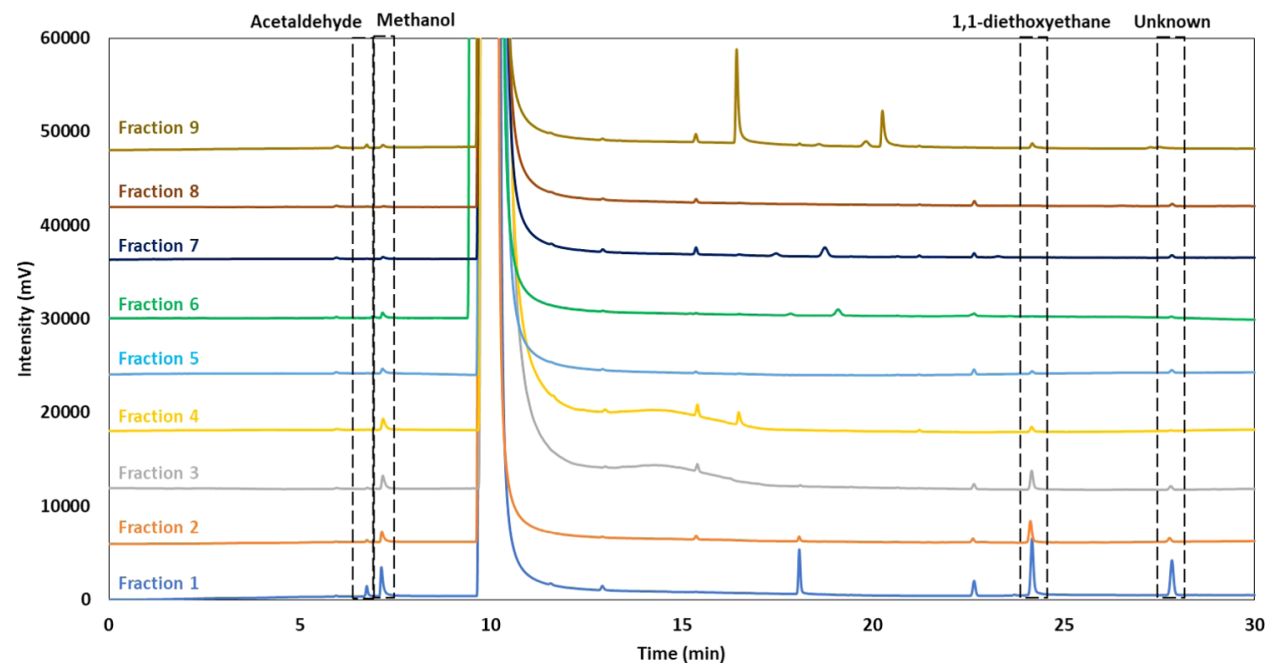

Figure 3. Chromatograms obtained for the different bioethanol distillation fractions.

methanol, 1-propanol, and 1,1-diethoxyethane were present in most of the samples. Isoamyl alcohol, in turn, was present in a lower number of samples than the previous compounds but, where present, its concentration was above $500 \mathrm{mg} \mathrm{L}^{-1}$ in a significant number of samples. Finally, it is worth noting that the highest-concentrated compound was methanol in sample $\mathrm{B} 18$ that was found at levels above $10 \mathrm{~g} \mathrm{~L}^{-1}$.

2.2.2.1. Effect of the Distillation Step. The samples labeled as fraction 1 (B22) to fraction 9 (B30) were taken from different steps of the same distillation process, where fraction 1 was the lightest fraction and fraction 9 the heaviest one. Figure 3 shows the obtained chromatograms revealing how peaks for acetaldehyde (i.e., a short peak found for fraction 1, just before the methanol peak), methanol, and 1,1-diethoxyethane present in the lightest fraction gradually disappeared from fraction 2 to fraction 9. In contrast, unidentified compounds, not present in the lightest fractions, were found in the heavy bioethanol ones. Some of them were further identified through GC-MS, and it was observed that the peak found for fraction 1 at a retention time close to $18 \mathrm{~min}$ (see Figure 3 ) corresponded to ethyl acetate. Meanwhile, the peaks that appeared at 16 and $20 \mathrm{~min}$ in the case of fraction 9 corresponded to 1-propanol and 2butanol, respectively.

2.2.2.2. Effect of the Storage Material. The influence of the material of the container in contact with the bioethanol samples on the volatile organic compounds present in the samples was checked. For this purpose, samples were stored in glass, Nalgene, high-density polyethylene (HDPE), and 
Table 3. Concentrations (in $\mathrm{mg} \mathrm{L}^{-1}$ ) of Organic Compounds Found in Samples Obtained from Different Raw Materials ${ }^{a}$

\begin{tabular}{|c|c|c|c|c|c|c|c|c|c|c|c|}
\hline compound & $\begin{array}{c}\text { B5 } \\
\text { (wheat 1) }\end{array}$ & $\begin{array}{c}\text { B7 } \\
\text { (beet) }\end{array}$ & $\begin{array}{c}\text { B8 } \\
\text { (beet 3) }\end{array}$ & $\begin{array}{c}\text { B9 } \\
\text { (beet 4) }\end{array}$ & $\begin{array}{c}\mathrm{B} 10 \\
\text { (beet 5) }\end{array}$ & $\begin{array}{c}\mathrm{B} 11 \\
\text { (beet 6) }\end{array}$ & $\begin{array}{c}\mathrm{B} 12 \\
\text { (beet 7) }\end{array}$ & $\begin{array}{c}\text { B13 } \\
\text { (cereal) }\end{array}$ & $\begin{array}{c}\text { B14 } \\
\text { (sugarcane) }\end{array}$ & $\begin{array}{l}\text { B17 (wine } \\
\text { residue 2) }\end{array}$ & $\begin{array}{l}\text { B18 (wine } \\
\text { residue) }\end{array}$ \\
\hline acetaldehyde & & 920 & 276 & & 422 & 510 & 442 & 1049 & 504 & 834 & \\
\hline methanol & & & 176 & & & & 181 & & & & 10398 \\
\hline 1-propanol & & 583 & 1659 & 295 & 473 & 875 & 297 & 355 & & 777 & 2498 \\
\hline 2-butanol & & & & & & & & & & & 801 \\
\hline$i$-butanol & & 507 & 838 & & 314 & 445 & & 327 & & 367 & 673 \\
\hline $\begin{array}{l}\text { 1,1- } \\
\text { diethoxyethane }\end{array}$ & & 905 & & & & & & 342 & & & 737 \\
\hline isoamyl alcohol & & & & & & & & & & & 715 \\
\hline
\end{tabular}

${ }^{a}$ Confidence levels $<10 \%$. Empty boxes correspond to concentrations below the limit of quantification.

poly(tetrafluoroethylene) (PTFE) for more than 12 months in a fridge at $4{ }^{\circ} \mathrm{C}$ and then analyzed. It was verified that the storage material did not have any effect on the content of volatile organic compounds, indicating that glass and the three polymers studied are stable in contact with bioethanol samples.

2.2.2.3. Bioethanol Samples Obtained from Different Raw Materials. Table 3 summarizes the found concentrations for first-generation bioethanol samples obtained using wheat, winemaking residues, beetroot, cereals, and sugarcane as raw materials. It can be observed that the bioethanol composition depended strongly on the source used for its production. Thus, winemaking residues (B18) and beet (B7) conferred the highest contents of organic products to the finally obtained alcohol. Other samples such as B17, B8, or B11 also contained high concentrations of compounds such as 1-propanol, 1,1diethoxyethane, and $i$-butanol. It has been indicated that isoamyl alcohols and butanol are produced when the raw materials contain molasses and fruits; this would explain the results found for $\mathrm{B} 18 .{ }^{35}$ In contrast, wheat and sugarcane are the raw materials providing the "cleanest" bioethanol. In fact, none of these major compounds has been found in the sample corresponding to wheat at concentrations above the limit of quantification of the technique. These observations are also related to the purity of these stocks.

In terms of species, the most often present is 1-propanol, being found in eight out of 11 samples analyzed. Interestingly, acetaldehyde and isobutanol used to be present in a large number of samples.

2.2.2.4. Hydrated Samples, Second-Generation Bioethanol, and Biobutanol. This group considers bioethanol obtained by means of different processes, samples with different water contents, second-generation bioethanol (B19), and a biobutanol sample (B39). It is important to remark that the latter sample contains around $4 \mathrm{~g} \mathrm{~L}^{-1} 1$-propanol and more than $1.5 \mathrm{~g} \mathrm{~L}^{-1}$ isoamyl alcohol (Table 4). Samples B40 and B42 correspond to the product obtained from beet raw materials (B41), following the bioethanol production process described in ref 27. As expected, the latter sample (B41) contained a higher concentration of additional products than the bioethanol obtained at the end of the process.

2.3. Evaluation of the Quality of the Analyzed Samples. The total content of nonethanol compounds was evaluated by considering the quantitative data provided by the GC-FID instrument. The results of the total concentration of VOCs are summarized in Figure 4. Interesting conclusions were drawn from these data. First, it was observed that, for wheat samples, the total content of organic compounds different from ethanol was virtually independent of the water percentage. Also interesting was to notice the great variability
Table 4. Concentrations (in $\mathrm{mg} \mathrm{L}^{-1}$ ) of Organic Compounds Found in Samples Obtained from Different Raw Materials with Different Water Contents, SecondGeneration Bioethanol, and Biobutanol ${ }^{a}$

\begin{tabular}{|c|c|c|c|c|c|c|c|c|c|c|c|c|c|}
\hline & 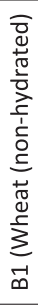 & 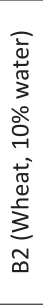 & 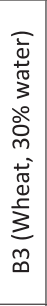 & 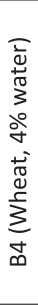 & 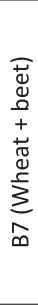 & 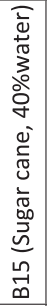 & 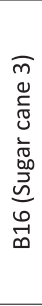 & 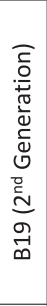 & 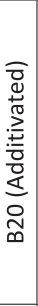 & 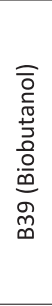 & 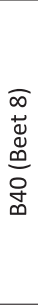 & 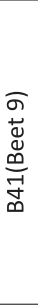 & 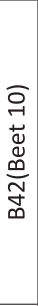 \\
\hline Acetaldehyde & $\begin{array}{c}64 \\
0\end{array}$ & $\begin{array}{c}54 \\
1\end{array}$ & $\begin{array}{c}32 \\
2\end{array}$ & & $\begin{array}{c}28 \\
1\end{array}$ & $\begin{array}{c}17 \\
5\end{array}$ & $\begin{array}{c}81 \\
0\end{array}$ & $\begin{array}{c}44 \\
2\end{array}$ & & & & $\begin{array}{c}41 \\
9\end{array}$ & \\
\hline Methanol & & & & & & & & $\begin{array}{c}82 \\
0\end{array}$ & & & & & \\
\hline 2-Propanol & & & & & & & $\begin{array}{c}11 \\
7 \\
\end{array}$ & & & & & & \\
\hline 1-Propanol & $\begin{array}{c}43 \\
3\end{array}$ & $\begin{array}{c}40 \\
7\end{array}$ & $\begin{array}{c}26 \\
8\end{array}$ & & $\begin{array}{c}62 \\
7\end{array}$ & $\begin{array}{c}36 \\
6\end{array}$ & $\begin{array}{c}21 \\
1\end{array}$ & & & $\begin{array}{c}390 \\
1\end{array}$ & & $\begin{array}{c}58 \\
9\end{array}$ & \\
\hline 2-Butanol & & & & & & & & & & 80 & & & \\
\hline i-Butanol & $\begin{array}{c}23 \\
3\end{array}$ & $\begin{array}{c}37 \\
6\end{array}$ & $\begin{array}{c}34 \\
2\end{array}$ & & $\begin{array}{c}32 \\
3\end{array}$ & & & & & & & $\begin{array}{c}30 \\
9\end{array}$ & \\
\hline $\begin{array}{c}1,1- \\
\text { Diethoxyethan } \\
\mathrm{e}\end{array}$ & $\begin{array}{c}15 \\
6\end{array}$ & & & & $\begin{array}{c}63 \\
8\end{array}$ & & $\begin{array}{c}36 \\
5\end{array}$ & & & & & & \\
\hline $\begin{array}{l}\text { Isoamyl } \\
\text { alcohol }\end{array}$ & & $\begin{array}{c}36 \\
1\end{array}$ & $\begin{array}{c}71 \\
2\end{array}$ & & & $\begin{array}{c}52 \\
3\end{array}$ & & $\begin{array}{c}30 \\
5\end{array}$ & & $\begin{array}{c}153 \\
6\end{array}$ & & & \\
\hline
\end{tabular}

${ }^{a}$ Confidence levels $<10 \%$.

in the total content of VOCs depending on the bioethanol produced from beet or sugarcane. Sample B18, issued from winery residues, presented by far the highest total concentration of organic compounds different from ethanol, likely because of the high methanol concentration (see Table 3). Bioethanol of the second generation had a level of VOCs similar to that for many first-generation ones.

Another interesting observation lied in the results found for the different distillation fractions because it was clearly observed that the total content of organic compounds different from ethanol decreased from B22 (the lightest fraction) to B29 (the heaviest one). This fact could be related to the removal of nonvolatile compounds during the distillation process (see Section 2.1.11 and Figure 2). In agreement with the previously shown data (Figure 2), the material of the container in which the samples were stored did not have any significant influence on the total concentration of quantified species and, finally, biobutanol presented a high concentration of volatile compounds. 


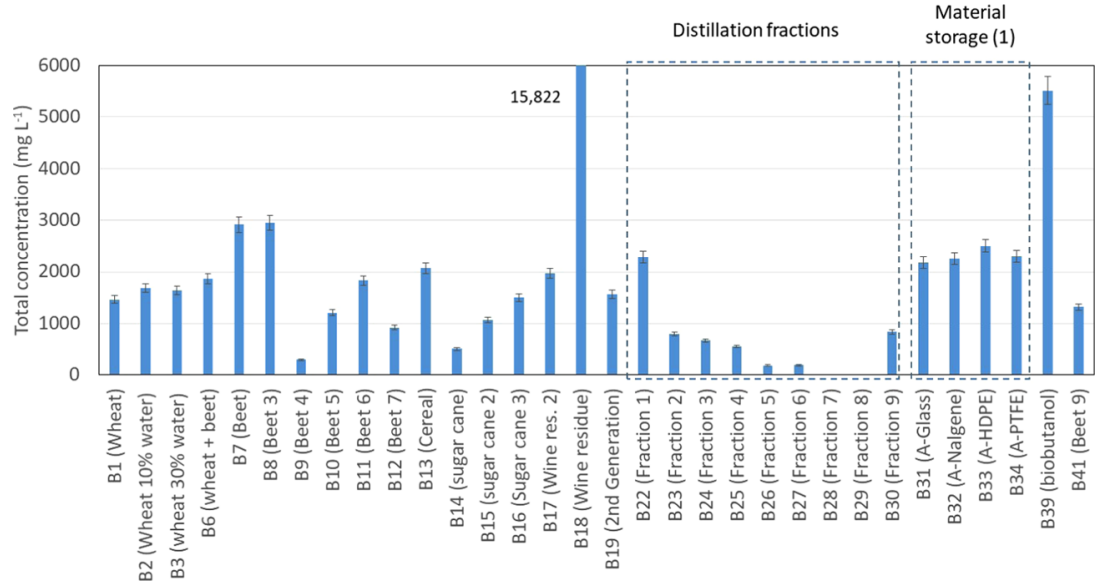

Figure 4. Total concentration of VOCs other than ethanol found in different samples.

Table 5. Relative Areas (\% with Respect to the Total Area) for the Aromatic Hydrocarbons Found through CG-MS in the Different Samples

\begin{tabular}{|c|c|c|c|c|c|c|c|c|c|c|c|c|c|c|c|c|c|c|c|}
\hline Compound & B1 & B11 & B13 & B15 & B16 & B19 & B21 & B22 & B23 & B24 & B25 & B26 & B27 & B28 & B29 & B39 & B40 & B41 & B42 \\
\hline Toluene / Methylbenzene & - & & & 0.74 & 0.66 & & 1.160 & 13.65 & 1.71 & 1.96 & 1.19 & 2.48 & 0.58 & 1.99 & 1.70 & & 0.88 & 62 & 30 \\
\hline Ethylbenzene & & 0.12 & & & & & 0.065 & & & & & & & & & & & - & \\
\hline p-xylene / 1,4-dimehtylbenzene & - & - & 0.2 & 0.72 & 0.63 & & 0.255 & 0.052 & 0.036 & 0.029 & 0.037 & 0.062 & 0.016 & & 0.049 & & - & 25.0 & 9.0 \\
\hline m-xylene / 1,3 dimethylbenzene & - & 0.32 & & - & 0.027 & & 0.121 & 0.021 & 0.014 & 0.033 & 0.028 & 0.032 & 0.050 & & 0.065 & & - & - & - \\
\hline Stirene / Ethenylbenzene & 0.26 & & & & & & & 0.031 & 0.035 & 0.057 & 0.053 & 0.098 & 0.025 & & & & & & \\
\hline o-xylene / 1,2-dimethylbenzene & & & & & & & 0.013 & & & & & & & & & & & - & \\
\hline m-ethyltoluene or o-methyltoluene & & & & & & & & & & & & & & & & 0.007 & & & \\
\hline 1,2,3-trymethylbenzene & & & & & & & & & & & & & & & & 0.012 & & - & \\
\hline 1,2,4-trymethylbenzene & & & & & & & & & & & & & & & & 0.014 & & - & \\
\hline 1,3,5-trimethylbenzene & & & & & & & & & & & & & & & & 0.015 & & - & \\
\hline 1,2,3,4-tetrahydro-1,1,6-trimethyl-1-napthalene & & & & & & 0.55 & & & & & & & & & & & & & \\
\hline 1,2-dihydro-1,1,6-trimethylnapthalene & & & & & & 0.73 & & & & & & & & & & & & & \\
\hline
\end{tabular}

Aromatic hydrocarbons were identified in some of the analyzed samples. Table 5 lists the relative peak area corresponding to this group of compounds only in the samples in which they were detected. It was clearly observed that among the samples evaluated, B41 and B42 presented the highest load of aromatic impurities, likely because both had a relatively high toluene concentration. B22 also contained a high toluene amount, whereas the remaining distillation fractions (B23-B30) did not. Although this compound is frequently observed in those samples that are polluted with aromatic compounds, it has not been never identified in bioethanol samples. The remaining aromatic compounds were present at actually low concentrations because the peak areas were very low.

To further test the quality of the bioethanol samples analyzed in the present work, the obtained results were compared against the maximum levels recommended by several standards (Table 1). Taking into account the achieved data, the samples studied contained levels of higher alcohols below the allowed maximum contents. B18 provided the highest value of this parameter with approximately $0.47 \%$, far below the maximum allowed values. A similar comment could be made in terms of methanol concentration with the exception of sample B18 (methanol concentration around $1.04 \%$ ). As Table 6 indicates, this was a sample originated from winemaking residues. According to the ASTM D5798 standard, this sample would not be appropriate for ethanol fuel blends used in flexible-fuel automotive spark-ignition engines. Standards EN 15376 and EN 15293, in contrast, could consider this bioethanol appropriate as an automotive ethanol (E85) fuel and as a blending component for petrol, respectively, although the determined concentration was just in the limit imposed by both standards.

\section{CONCLUSIONS}

More than 100 different VOCs were identified in bioethanol samples. Some of these compounds can be directly extracted from the raw material, such as limonene, organic acids, and aromatic hydrocarbons. Nevertheless, other VOCs, such as alcohols or acetaldehyde, appear as byproducts of the 
Table 6. Description of the Studied Samples

\begin{tabular}{|c|c|c|}
\hline code & sample name & description \\
\hline B1 & wheat & bioethanol from wheat, nonhydrated \\
\hline $\mathrm{B} 2$ & wheat $90 \%$ & bioethanol from wheat, $10 \%$ water \\
\hline B3 & wheat $70 \%$ & bioethanol from wheat, $30 \%$ water \\
\hline B4 & wheat $96 \%$ & bioethanol from wheat, $4 \%$ water \\
\hline B5 & wheat 1 & bioethanol nonhydrated from wheat \\
\hline B6 & wheat + beet & $\begin{array}{l}\text { bioethanol from a mixture of wheat and beet, } \\
\text { nonhydrated }\end{array}$ \\
\hline B7 & beet & bioethanol from beet \\
\hline B8 & beet 3 & bioethanol from beet 3 \\
\hline B9 & beet 4 & bioethanol from beet 4 \\
\hline B10 & beet 5 & bioethanol from beet 5 \\
\hline B11 & beet 6 & bioethanol from beet 6 \\
\hline B12 & beet 7 & bioethanol from beet 7 \\
\hline B13 & cereal & bioethanol from cereal \\
\hline B14 & sugarcane 1 & bioethanol from sugarcane, hydrated \\
\hline B15 & sugarcane 2 & bioethanol from sugarcane, $40 \%$ water \\
\hline B16 & sugarcane 3 & bioethanol from sugarcane \\
\hline B17 & wine residue 2 & bioethanol from winemaking residues \\
\hline B18 & wine residue & bioethanol from winemaking residues \\
\hline B19 & $\begin{array}{l}\text { second } \\
\text { generation }\end{array}$ & lignocellulosic bioethanol (2nd generation) \\
\hline B20 & additivated & bioethanol additivated, nonhydrated \\
\hline B21 & $\begin{array}{l}\text { distilled } \\
\text { sample }\end{array}$ & $\begin{array}{l}\text { sugar beet bioethanol containing } 20 \% \text { of water } \\
\text { yielding to nine different fractions (B22-B30) }\end{array}$ \\
\hline B22 & fraction 1 & $\begin{array}{l}\text { fraction of distillation } 1 \text { (lightest fraction), sample } \\
\text { B21 }\end{array}$ \\
\hline B23 & fraction 2 & fraction of distillation 2, sample B21 \\
\hline B24 & fraction 3 & fraction of distillation 3 , sample B21 \\
\hline B25 & fraction 4 & fraction of distillation 4 , sample B21 \\
\hline B26 & fraction 5 & fraction of distillation 5, sample B21 \\
\hline B27 & fraction 6 & fraction of distillation 6 , sample B21 \\
\hline B28 & fraction 7 & fraction of distillation 7 , sample B21 \\
\hline B29 & fraction 8 & fraction of distillation 8 , sample B21 \\
\hline $\mathrm{B} 30$ & fraction 9 & $\begin{array}{l}\text { fraction of distillation } 9 \text { (heaviest fraction), sample } \\
\text { B21 }\end{array}$ \\
\hline B31 & A-glass & bioethanol sample B3 stored in glass \\
\hline B32 & A-Nalgene & bioethanol sample B3 stored in Nalgene \\
\hline B33 & A-HDPE & bioethanol sample B3 stored in HDPE \\
\hline B34 & A-PTFE & bioethanol sample B3 stored in PTFE \\
\hline B35 & B-glass & bioethanol sample B20 stored in glass \\
\hline B36 & B-Nalgene & bioethanol sample B20 stored in Nalgene \\
\hline B37 & B-HDPE & bioethanol sample B20 stored in HDPE \\
\hline B38 & B-PTFE & bioethanol sample B20 stored in PTFE \\
\hline B39 & biobutanol & fermented must biobutanol \\
\hline B40 & beet 8 & $\begin{array}{l}\text { final dehydrated bioethanol sample issuing from the } \\
\text { process described in ref } 27\end{array}$ \\
\hline B41 & beet 9 & $\begin{array}{l}\text { final raw bioethanol sample issuing from the } \\
\text { process described in ref } 27\end{array}$ \\
\hline B42 & beet 10 & $\begin{array}{l}\text { final dehydrated bioethanol sample issuing from the } \\
\text { process described in ref } 27\end{array}$ \\
\hline
\end{tabular}

fermentation process. Finally, other groups of organic compounds can be generated in the samples after their production by means of reactions favored by slightly acidic conditions. Among these compounds, esters (especially FAEEs) and 1,1-diethoxyethane are present in almost all of the samples. These results indicate that bioethanol samples have a complex matrix, with variable water content ranging from 0 to $7 \%$ and VOCs at concentrations on the order of tens of $\mathrm{g} \mathrm{L}^{-1}$ (the total amount of VOCs in bioethanol samples is up to $2.5 \%$ ).
It has been demonstrated that the material in which the sample is stored does not have any effect on the organic compound profile of the sample. Additionally, it has been reported that those organic compounds with low boiling points (lower or similar to that of ethanol) appear in the bioethanol samples because the distillation is not effective for their removal. Moreover, second-generation samples presented the highest number of organic compounds in their matrixes. When simple sugars sources as cereals, wheat, or beetroot are selected to produce bioethanol, fewer organics are identified. These results can be associated with a simple fermentation and it is, consequently, reflected in the lower number of byproducts resulting from this process. Finally, $i$-butanol was identified as the major component of the matrix of a biobutanol sample. The number of organic compounds was also higher than the average in the rest of the samples. This fact could also be associated with the production process, which is more complex than in the case of first-generation bioethanol.

Alcohols and esters were the most important contributors to the total VOCs in the bioethanol samples analyzed. However, it is also necessary to carefully monitor other minor and trace VOCs that have been identified in bioethanol samples, such as benzene, toluene, ethylbenzene, or xylene (BTEX), since they may cause drastic damage to the human health when they are emitted to the atmosphere, even at very low concentrations.

All of these observations revealed the importance of carrying out the production of bioethanol under controlled conditions since slight changes in any of the steps may modify the profile of organic compounds present in the final product. For instance, it has been observed that the $\mathrm{pH}$ during the fermentation step has a direct influence on the alcohol composition of the finally obtained products. Additionally, transportation and storage conditions of this biofuel should also be controlled because some of the organic products are the result of postproduction reactions and changes in $\mathrm{pH}$, humidity, or temperature, thus affecting the bioethanol quality.

Finally, despite the fact that multiple organic species are found in the evaluated samples, it has been observed that virtually all of them were in agreement with the standards on fuel composition. Only for a compound (i.e., methanol) in a sample (i.e., bioethanol issued from winery residues), the sample was not appropriate for fuel applications.

\section{EXPERIMENTAL SECTION}

4.1. Reagents, Standards, and Samples. A multicompound standard solution was prepared to contain 2000 mg $\mathrm{L}^{-1}$ methanol (Sigma-Aldrich, St. Louis), 1-propanol (Sigma-Aldrich, St. Louis), 2-propanol (Sigma-Aldrich, St. Louis), 1-butanol (Merck, Darmstadt, Germany), 2-butanol (Merck, Darmstadt, Germany), i-butanol (Sigma-Aldrich, St. Louis), isoamyl alcohol (Merck, Darmstadt, Germany), acetone (Sigma-Aldrich, St. Louis), acetaldehyde (Merck, Darmstadt, Germany), and 1,1-diethoxyethane (Sigma-Aldrich, St. Louis). All of these chemicals were of GC-MS grade, thus ensuring that the standard was not polluted with other compounds or they were in concentrations below the limit of quantification, LOQ. The calibration standards used in GCFID were prepared by dilution of this multicompound standard with absolute ethanol (Panreac, Barcelona, Spain). The analyte concentrations ranged from 20 to $2000 \mathrm{mg} \mathrm{L}^{-1}$.

Forty-two bioethanol real samples of different geographical origins, from different raw materials, and following different treatments were analyzed (see Table 6). For the sake of clarity, 
the samples were grouped into five categories: (i) samples obtained from different raw materials (winemaking residues, cereal, sugar beet) following the same production process; (ii) nine fractions of the distillation of a given bioethanol sample; (iii) a second-generation bioethanol sample; (iv) a sample of biobutanol issued from fermented must distillation; and ( $\mathrm{v}$ ) bioethanol samples stored in several materials (glass, Nalgene, PTFE, HDPE).

4.2. Gas Chromatography-Mass Spectrometry (GCMS). An Agilent $6890 \mathrm{~N}$ gas chromatography system (Agilent, Santa Clara) coupled to an Agilent 5973N mass spectrometer (Agilent, Santa Clara) with an electron impact ion source was used to carry out the identification of volatile compounds in bioethanol samples. The column chosen was a DB-624 (Agilent, Santa Clara). The characteristics of the column and operating conditions are presented in Table 7.

Table 7. GC-MS and GC-FID Operating Conditions and Column Characteristics

\begin{tabular}{|c|c|c|}
\hline & GC-MS & GC-FID \\
\hline temperature $T_{1}$ [time] & $35^{\circ} \mathrm{C}[10 \mathrm{~min}]$ & $40{ }^{\circ} \mathrm{C}[12 \mathrm{~min}]$ \\
\hline $\begin{array}{l}\text { temperature ramp } 1 \\
\qquad\left[T_{1}-T_{2}\right]\end{array}$ & $\begin{array}{l}10{ }^{\circ} \mathrm{C} \min ^{-1} \\
{\left[35-100{ }^{\circ} \mathrm{C}\right]}\end{array}$ & $\begin{array}{l}10{ }^{\circ} \mathrm{C} \min ^{-1} \\
{\left[40-100{ }^{\circ} \mathrm{C}\right]}\end{array}$ \\
\hline $\begin{array}{l}\text { temperature ramp } 2 \\
\qquad\left[T_{2}-T_{3}\right]\end{array}$ & $\begin{array}{l}20{ }^{\circ} \mathrm{C} \mathrm{min} \min ^{-1} \\
{\left[100-225^{\circ} \mathrm{C}\right]}\end{array}$ & \\
\hline temperature $T_{2}$ [time] & $225^{\circ} \mathrm{C}[10 \mathrm{~min}]$ & $100{ }^{\circ} \mathrm{C}[12 \mathrm{~min}]$ \\
\hline injector temperature & \multicolumn{2}{|c|}{$250{ }^{\circ} \mathrm{C}$} \\
\hline split & $1: 10$ & $1: 100$ \\
\hline detector temperature & \multicolumn{2}{|c|}{$250^{\circ} \mathrm{C}$} \\
\hline $\begin{array}{l}\text { carrier (helium) gas flow } \\
\text { rate }\end{array}$ & \multicolumn{2}{|c|}{$1.3 \mathrm{~mL} \mathrm{~min}^{-1}$} \\
\hline model & J\&W DB-624 (Agilent) & TRB-624 Teknokroma \\
\hline stationary phase & \multicolumn{2}{|c|}{$\begin{array}{l}6 \% \text { cyanopropyl-phenyl-94\% } \\
\text { dimethylpolysiloxane cross-linked }\end{array}$} \\
\hline
\end{tabular}

4.3. Gas Chromatography-Flame Ionization Detection (GC-FID). A GC-2014 Shimadzu GC-FID (Shimadzu Corp., Kyoto, Japan) was used to carry out the quantification of volatile compounds (Table 7). The selected column was a TRB-624 (Teknokroma, Barcelona, Spain).

To avoid peak overlapping and simultaneously shortening the analysis time, the temperature gradient detailed in Table 7 was applied. Under these conditions, the analysis time was 30 min with good resolution (all of the calculated $R_{\mathrm{s}}$ values being higher than 3.2) and an acceptable signal-to-noise ratio. In general terms, for a given group of compounds, the retention time increased with the boiling point. Limits of quantification achieved for the determined compounds are summarized in Table S1.

\section{ASSOCIATED CONTENT}

\section{SI Supporting Information}

The Supporting Information is available free of charge at https://pubs.acs.org/doi/10.1021/acsomega.0c02360.

Limits of quantification for ten different organic compounds obtained through GC-FID (Table S1) and compounds identified by means of GC-MS in the analyzed samples according to the following functional groups: alcohols (Table S2), aldehydes and ketones (Table S3), esters (Table S4), ethers (Table S5), hydrocarbons (Table S6), aromatic hydrocarbons (Table S7), nitrogen-containing compounds (Table
S8), organic acids (Table S9), furane derivates (Table S10), and other organic compounds (Table S11) (PDF)

\section{AUTHOR INFORMATION}

\section{Corresponding Author}

José-Luis Todolí - Department of Analytical Chemistry,

Nutrition and Food Sciences, University of Alicante, 03080

Alicante, Spain; 이이.org/0000-0002-9151-7050;

Email: jose.todoli@ua.es

\section{Authors \\ Carlos Sánchez - Department of Analytical Chemistry, Nutrition and Food Sciences, University of Alicante, 03080 Alicante, Spain \\ Sergio Santos - Department of Analytical Chemistry, Nutrition and Food Sciences, University of Alicante, 03080 Alicante, Spain \\ Raquel Sánchez - Department of Analytical Chemistry, Nutrition and Food Sciences, University of Alicante, 03080 Alicante, Spain; ○ orcid.org/0000-0003-0283-6103 \\ Charles-Philippe Lienemann - IFP Energies Nouvelles, F- 69360 Solaize, France}

Complete contact information is available at:

https://pubs.acs.org/10.1021/acsomega.0c02360

\section{Notes}

The authors declare no competing financial interest.

\section{ACKNOWLEDGMENTS}

Authors are grateful to the Spanish Ministry of Science, Innovation and Universities for the financial support (Project Ref. PGC2018-100711-B-I00). C.S. thanks to the Ministry of Education, Spain for the contract FPU 13/01438. The authors also thank J.P. Vidal from UNGDA for providing some of the analyzed samples together with valuable information about their nature.

\section{REFERENCES}

(1) Demirbas, A. Competitive liquid biofuels from biomass. Appl. Energy 2011, 88, 17-28.

(2) Köpke, M.; Dürre, P. Biochemical Production of Bioethanol. In Handbook of Biofuels Production, Processes and Technologies; Woodhead Publishing Limited, 2011; pp 221-257.

(3) Walker, G. M. Bioethanol: Science and Technology of Fuel Alcohol; Ventus Publishing ApS, 2010.

(4) Wheals, A. E.; Basso, L. C.; Alves, D. M. G.; Amorim, H. V. Fuel ethanol after 25 years. Trends Biotechnol. 1999, 17, 482-487.

(5) Sánchez, R.; Sánchez, C.; Lienemann, C.-P.; Todolí, J.-L. Metal and metalloid determination in biodiesel and bioethanol. J. Anal. At. Spectrom. 2015, 30, 64-101.

(6) Monot, F.; Margeot, A.; Hahn-Hägerdal, B.; Lindstedt, J.; Slade, R. The NILE Project-Advances in the Conversion of Lignocellulosic Materials into Ethanol. Oil Gas Sci. Technol. 2013, 68, 693-705.

(7) Lemos, P.; Mesquita, F. C. Future of Global Bioethanol: An Appraisal of Results, Risk and Uncertainties. In Global Bioethanol; Elsevier Inc., 2016; pp 221-237.

(8) Balat, M.; Balat, H. Recent trends in global production and utilization of bio-ethanol fuel. Appl. Energy 2009, 86, 2273-2282.

(9) Nigam, P. S.; Singh, A. Production of liquid biofuels from renewable resources. Prog. Energy Combust. Sci. 2011, 37, 52-68.

(10) Niven, R. K. Ethanol in gasoline: Environmental impacts and sustainability review article. Renew. Sustainable Energy Rev. 2005, 9, $535-555$

(11) Ho, D. P.; Ngo, H. H.; Guo, W. A mini review on renewable sources for biofuel. Bioresour. Technol. 2014, 169, 742-749. 
(12) Patil, V.; Tran, K. Q.; Giselrød, H. R. Towards sustainable production of biofuels from microalgae. Int. J. Mol. Sci. 2008, 9, $1188-1195$.

(13) Habe, H.; Shinbo, T.; Yamamoto, T.; Sato, S.; Shimada, H.; Sakaki, K. Chemical Analysis of Impurities in Diverse Bioethanol Samples. J. Jpn. Pet. Inst. 2013, 56, 414-422.

(14) Sánchez, C.; Lienemann, C.-P.; Todolí, J.-L. Analysis of bioethanol samples through Inductively Coupled Plasma Mass Spectrometry with a total sample consumption system. Spectrochim. Acta, Part B 2016, 124, 99-108.

(15) Sánchez, C.; Lienemann, C.-P.; Todolí, J.-L. Metal and metalloid determination in bioethanol through inductively coupled plasma-optical emission spectroscopy. Spectrochim. Acta, Part B 2016, $115,16-22$.

(16) Chiche, D.; Diverchy, C.; Lucquin, A. C.; Porcheron, F.; Defoort, F. Synthesis Gas Purification. Oil Gas Sci. Technol. 2013, 68, $707-723$.

(17) Anderson, L. G. Ethanol fuel use in Brazil: air quality impacts. Energy Environ. Sci. 2009, 2, 1015.

(18) Styarini, D.; Aristiawan, Y.; Aulia, F.; Abimanyu, H.; Sudiyani, Y. Determination of organic impurities in lignocellulosic bioethanol product by GC-FID. Energy Procedia 2013, 32, 153-159.

(19) ASTM D5798: Standard Specification for Ethanol Fuel Blends for Flexible-Fuel Automotive Spark-Ignition Engines, March 2018.

(20) EN 15376: Automotive Fuels-Ethanol as a Blending Component For Petrol-Requirements and Test Methods, February 2015.

(21) EN 15293: Automotive Fuels. Automotive Ethanol (E85) Fuel. Requirements and Test Methods, May 2019.

(22) ASTM E3050: Standard Specification for Denatured Ethanol for Use as Cooking and Appliance Fuel, September 2019.

(23) ASTM E3237: Standard Specification for Undenatured Ethanol from Biomass for Use in Industrial Applications, September 2019.

(24) Rathour, R. K.; Ahuja, V.; Bhatia, R. K.; Bhatt, A. K. Biobutanol: New era of biofuels. Int. J. Energy Res. 2018, 42, 45324545.

(25) Ribéreau-Gayon, P.; Glories, Y.; Maujean, A.; Dubourdieu, D. Handbook of Enology. In The Chemistry of Wine; John Wiley \& Sons Ltd.: Paris, 2006; Vol. 2.

(26) Kłosowski, G.; Mikulski, D.; Grajewski, J.; Blajet-Kosicka, A. The influence of raw material contamination with mycotoxins on alcoholic fermentation indicator. Bioresour. Technol. 2010, 101, 31473152.

(27) Sánchez, C.; Vidal, J.-P.; Lienemann, C.-P.; Todolí, J.-L. Evolution of the metal and metalloid content along the bioethanol production process. Fuel Process. Technol. 2018, 173, 1-10.

(28) Gomez, M. F.; Arrúa, L. A.; Abello, M. C. Synthesis of 1,1diethoxyethane from bioethanol. Influence of catalyst acidity. React. Kinet. Catal. Lett. 2001, 73, 143-149.

(29) Ladygina, N.; Dedyukhina, E. G.; Vainshtein, M. B. A review on microbial synthesis of hydrocarbons. Process Biochem. 2006, 41, 1001-1014.

(30) Shin, G. J.; Jeong, S. Y.; Lee, J. W. Evaluation of antioxidant activity of the residues generated from ethanol concentration of lignocellulosic biomass using pervaporation. J. Ind. Eng. Chem. 2017, $52,51-58$.

(31) Thomas, T. H.; Kendrick, T. C. Thermal analysis of polydimethylsiloxanes. I. Thermal degradation in controlled atmospheres. J. Polym. Sci., Part A-2: Polym. Phys. 1969, 7, 537-549.

(32) Han, X.; Naeher, L. P. A review of traffic-related air pollution exposure assessment studies in the developing world. Environ. Int. 2006, 32, 106-120.

(33) Zhang, K.; Batterman, S. Air pollution and health risks due to vehicle traffic. Sci. Total Environ. 2013, 450-451, 307-316.

(34) Andrews, D. U.; et al. Photo-Tautomerization of Acetaldehyde to Vinyl Alcohol: A Potential Route to Tropospheric Acids. Science 2012, 337, 1203-1206.

(35) Roehr, M. The Biotechnology of Ethanol. In Classical and Future Applications; Wiley-VCH Verlag GmbH: Weinheim, 2001. 